\title{
Mitochondrial DNA genetic diversity of honey bees, Apis mellifera, in Hawaii
}

\author{
Allen L. Szalanski ${ }^{1}$, Amber D. Tripodi ${ }^{1,2}$, Clinton E. TrAmmel $^{1}$, Danielle DowneY ${ }^{3}$ \\ ${ }^{1}$ Department of Entomology, University of Arkansas, Fayetteville, AR 72701, USA \\ ${ }^{2}$ USDA-ARS, Pollinating Insects Research Unit, Logan, UT 84322, USA \\ ${ }^{3}$ Hawaii Department of Agriculture, Hilo, HI 96720, USA
}

Received 20 March 2015 - Revised 14 August 2015 - Accepted 13 November 2015

\begin{abstract}
Honey bees, Apis mellifera, in the Hawaiian Islands are geographically isolated from honey bees in mainland United States. We conducted a study on the mitochondrial DNA genetic diversity of honey bees from seven of the Hawaiian Islands by sequencing the intergenic region between the Cytochrome Oxidase I and Cytochrome Oxidase II genes (COI-COII). We observed a total of 10 haplotypes from 235 samples collected from 2009 to 2014. Haplotypes belonged to the A. mellifera C lineage (64\%), M lineage (35\%), and O lineage (1\%). Four of the five $\mathrm{C}$ lineage haplotypes found were common among queen breeders in continental United States $(\mathrm{C} 1$, $\mathrm{C} 2, \mathrm{C} 11, \mathrm{C} 19)$ and accounted for $99 \%$ of the C lineage bees. Haplotype C33 (1 \%) has been observed in feral honey bee populations in continental United States. For the M lineage, which includes the dark honey bee, A. m. mellifera, four haplotypes were observed (M3, M4c"', M7 and M70), with a novel haplotype unique to Hawaii, M70, being the second most common. Five islands had $\mathrm{M}$ lineage haplotypes, with their frequency ranging from $70 \%$ on Maui to $22 \%$ on Molokai. Two individuals of the O lineage, haplotype O1, were found on Oahu. Among the islands, Oahu and Maui, had the greatest amount of haplotypic diversity (haplotypic diversity $\left(H_{d}\right)=0.76$ and 0.75 ). Lanai and Kahoolawe had only one haplotype, $\mathrm{C} 1$, present.
\end{abstract}

\section{Apis mellifera / mtDNA / genetic diversity / island biogeography}

\section{INTRODUCTION}

The Hawaiian archipelago consists of eight islands ranging from 115.5 to $10,432.5 \mathrm{~km}^{2}$ in size located approximately $3200 \mathrm{~km}$ southwest of the North American mainland. The biota of the Hawaiian archipelago is known for its high levels of endemism and represents a microcosm for studies in evolution and conservation (Roderick and Gillespie 1998). Honey bees, Apis mellifera L., were first introduced to Hawaii in 1857 from California when four colonies of the dark honey bee, A. m. mellifera L., were shipped to Honolulu,

Corresponding author: A. Szalanski, aszalan@uark.edu

Manuscript editor: Yves Le Conte
Oahu from San Jose, California (Nieman 1942; Eckert 1951). Honey bee colonies were then introduced to all eight of the Hawaiian Islands, with 20,000 colonies in Hawaii by 1909 (Fullaway 1909). Currently, the number of managed honey bee colonies in Hawaii is approximately 16,310 with the following breakdown: Hawaii (Big Island), 14,000; Kauai, 1000; Oahu, 600; Maui, 500; Molokai, 200; and Lanai, 10 (DD, unpublished data; Figure 1). With concerns over the introduction of honey bee pathogens and parasites, Hawaii instituted a ban on the importation of packaged bees in 1908 (Roddy and Arita-Tsutsumi 1997), although breeder queens were brought in selectively until the early 1980s, and sperm is still imported. Due to the geographical isolation from continental United States, honey bees in Hawaii may have traits that are different from honey bees in the mainland. For example, Eckert (1950) found 


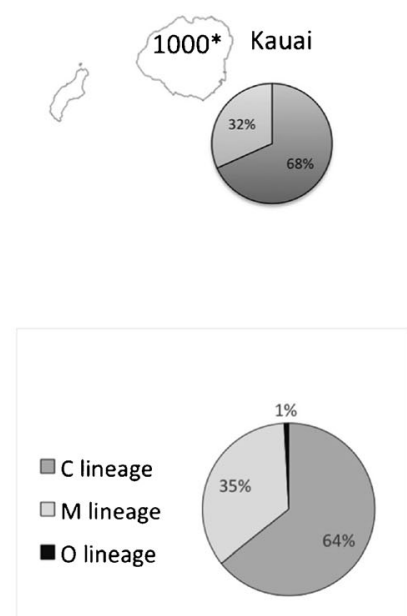

All Islands

*Estimated number of managed honey bee colonies

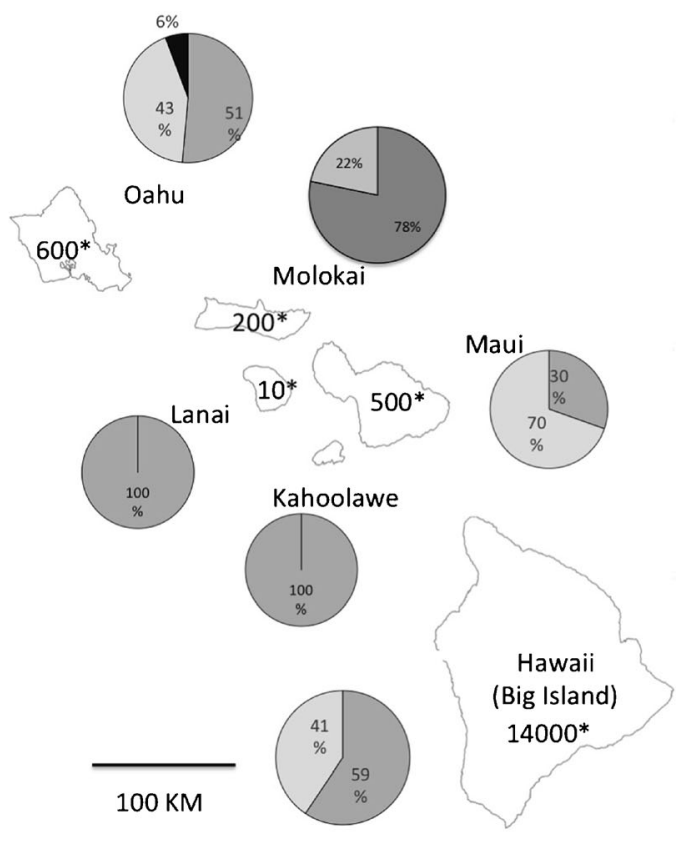

Figure 1. Percentage of A. mellifera mtDNA COI-COII lineages among seven Hawaiian Islands and the estimated number of colonies managed on each island

evidence that honey bees from Molokai may have resistance to American Foulbrood, Paenibacillus larvae. Additionally, the limited queen importations may have isolated the matrilines of Hawaiian bees, relative to continental populations.

Several ecological factors make beekeeping different and important in Hawaii relative to continental United States. For example, unlike most queen rearing regions of continental United States, Hawaii has year-round brood rearing which can increase the pressure from pathogens and parasites compared to climates with cold winters. These factors may result in lineage differences between Hawaiian and mainland honey bee populations, as beekeepers choose the strains that are hardiest in their own regions. Economically, Hawaii is not one of the largest honey producing states in the United States, but it is the third most efficient in terms of pounds produced per hive (Anonymous 2014). Even more notable is Hawaii's role as a provider of queens, producing more than 250,000 queens annually (Danka et al. 2010). Canadian beekeepers depend heavily on Hawaiian reared queens, with Hawaiian queens accounting for $83 \%$ of the
106,266 queens imported to Canada in 2003 (Anonymous 2005).

Honey bees have been placed into five evolutionary lineages, C (Eastern European), M (Western European), O (Oriental), A (African), and Y (Yemenitica), based on morphometric differences and their natural geographic distribution (Ruttner 1988; Sheppard et al. 1997; Sheppard and Meixner 2003). The M lineage, e.g., Apis $m$. mellifera (dark honey bee), has a reputation for being hardy, yet being nervous on the honey comb and easily defensive (Ruttner 1988). The C lineage includes $A$. m. carnica Pollman and $A . m$. ligustica Spinola (Ruttner 1988). This lineage has became preferred by most beekeepers and is bred by nearly all commercial beekeepers in the continental United States (Sheppard 1988, 1989a, b; Schiff and Sheppard 1996). Although there are five mitochondrial DNA (mtDNA) lineages worldwide, managed honey bees in the USA are dominated by the C lineage (Delaney et al. 2009; Magnus et al. 2011). with the $\mathrm{M}$ lineage and $\mathrm{O}$ lineages comprising 7 and $9 \%$ of unmanaged honey bees (excluding A lineage) in the United States (Magnus et al. 2014). 
It has been documented that honey bees of both the $\mathrm{M}$ and $\mathrm{C}$ lineages were introduced to Hawaii prior to the 1908 importation ban of honey bee colonies (Nieman 1942; Keck 1937). In Hawaii, some speculate that the $\mathrm{M}$ lineage still exists. For example, Messing (1991) observed that the occasionally aggressive "Hawaiian" honey bees were due to a "cross" between dark European honey bees and Italian bees. Tillman (1982) also noted that queen honey bees produced on Hawaii (Big Island) were a hybrid of queens mating with feral drones on the island which "came from German black bee stock." There is evidence that breeder queens have been brought to Hawaii from the continental United States in limited quantities since the 1908 importation ban (Tillman 1982).

DNA sequence analysis of the mtDNA cytochrome oxidase I-II (COI-COII) intergenic region can group honey bee subspecies to lineage by matriline as well as identify haplotypes within each lineage (Franck et al. 2001; Meixner et al. 2013). This classification method has been used for honey bees around the world, including in the continental United States (Delaney et al. 2009; Magnus and Szalanski 2010; Szalanski and Magnus 2010; Magnus et al. 2011, 2014) and Australia (Chapman et al. 2008). Unlike nuclear genotypes which can be altered during segregation or recombination during reproduction, mtDNA markers are maternally inherited intact, thus allowing mtDNA analysis to focus on the genealogies of individual lineages (Lansman et al. 1981). This also allows the use of a single individual to genetically characterize a colony (Sheppard and Smith 2000).

The purpose of this study was to characterize the maternally derived genetic diversity of honey bees from managed colonies, feral colonies, and swarms among the Hawaiian Islands using COICOII mtDNA sequence data.

\section{MATERIALS AND METHODS}

\subsection{Sampling}

Adult worker honey bees were collected from feral colonies, swarms, and managed (source types) colonies $(n=235)$ from the Hawaiian Islands: Kaua; Oahu; Molokai; Lanai; Maui;
Kahoolawe; and Hawaii (Big Island) from 2009 to 2014 (Table I). Following Schiff et al. (1994). feral colonies are defined as established colonies occurring in unmanaged homesites (e.g., trees, caves, buildings) or established colonies collected by beekeepers from unmanaged sites and placed in a managed apiary. Samples collected from swarm traps are defined as swarms. Samples were preserved in 70-100\% ethanol and sent to the Insect Genetics Lab, University of Arkansas, Fayetteville, Arkansas, for genetic analysis.

\subsection{Mitochondrial DNA analysis}

DNA was extracted from individual honey bee thoraces using a salting-out protocol with inhouse reagents (Sambrook and Russell 2001). PCR primers E2 (5'-GGC AGA ATA AGT GCA TTG-3') and H2 (5'-CAA TAT CAT TGA TGA CC-3') (Garnery et al. 1998) were used to amplify extracted DNA via PCR in a Biorad C1000 (Biorad, Hercules, CA). These primers amplify an approximately 530 to $1230 \mathrm{bp}$ fragment of the mtDNA COI-COII gene region. The length of the fragment depends on the many small and large indels, presence or absence of the P element, and variable number of $Q$ elements (Meixner et al. 2013). A total of $2 \mu \mathrm{L}$ of extracted DNA was used for PCR, and the remainder of the PCR reaction mixture followed Taylor et al. (1997). The PCR temperature profile consisted of holding the samples for $5 \mathrm{~min}$ at $94{ }^{\circ} \mathrm{C}$, and then 40 cycles of $94{ }^{\circ} \mathrm{C}$ for $45 \mathrm{~s}, 46{ }^{\circ} \mathrm{C}$ for $1 \mathrm{~min}$, and $72{ }^{\circ} \mathrm{C}$ for $1 \mathrm{~min}$, followed by a final extension of $72{ }^{\circ} \mathrm{C}$ for $5 \mathrm{~min}$. Amplicon verification was conducted by gel electrophoresis using $2 \%$ agarose gels, and PCR products were visualized using a BioDocit $^{\mathrm{TM}}$ Imaging System (UVP, Inc., Upland, CA). One honey bee worker from each sampled colony was subjected to DNA extraction and PCR of a portion of the mitochondrial DNA COI-COII region. Samples were purified and concentrated with VWR centrifugal devices (VWR, Radnor, PA) and sent to Eurofins Genomics (Huntsville, AL) for direct sequencing in both directions. The DNA sequence new to this study (haplotype M70) has been deposited in GenBank (Accession number KP059881). 
Table I. Sampling locations and source types

\begin{tabular}{lllll}
\hline Island & Sample sites & Feral & Swarm & Managed \\
\hline Hawaii & 38 & 3 & 8 & 58 \\
Kauai & 26 & 4 & 12 & 24 \\
Kahoolawe & 1 & 1 & 0 & 0 \\
Lanai & 19 & 9 & 4 & 8 \\
Maui & 13 & 4 & 0 & 19 \\
Molokai & 33 & 21 & 11 & 14 \\
Oahu & 16 & 0 & 3 & 32 \\
total & 146 & 42 & 38 & 155 \\
\hline
\end{tabular}

Voucher specimens are deposited at the University of Arkansas Insect Genetics Laboratory in Fayetteville, Arkansas, USA.

\subsection{Data analysis}

Consensus sequences with the primer ends removed were obtained using Geneious v6.1.6 (Biomatters Ltd., Auckland, New Zealand), and unique haplotypes were visually screened for nucleotide polymorphisms. Assignment and comparison of haplotypes was conducted by a NIH BLAST search of DNA sequences available on GenBank (http://blast.ncbi.nlm.nih.gov/ Blast.cgi). DNA sequence alignment of the haplotypes found in this study was done with Geneious with the first 165 bp of haplotypes M70 and M4c" removed to facilitate alignment. Haplotypic diversity $\left(H_{d}\right)$ was calculated with Arlequin v3.5 1.2 (Excoffier and Lischer 2010). Differentiation among islands was estimated with $F$-statistics ( $F_{\text {ST, }}$ Wright 1965$)$ using pairwise nucleotide differences within Arlequin v3.5 1.2 (Excoffier and Lischer 2010) and 16,000 permutations to determine significance (Excoffier and Lischer 2010). The estimated number of migrants shared between populations $\left(N_{m}\right)$ was calculated from the $F_{\mathrm{ST}}$ values using the formula $N_{m}=$ $\left(1-F_{\mathrm{ST}}\right) / 2 F_{\mathrm{ST}}$ for haploid data.

\section{RESULTS AND DISCUSSION}

A total of 235 honey bee samples were collected from Kauai, Oahu, Molokai, Lanai, Maui, Kahoolawe, and Hawaii (Big Island) and successfully sequenced (Table I). From the 146 sampling locations, 42 feral colonies, 38 swarms, and 155 managed honey bee colonies were sampled. Hawaii (Big Island) had the most samples, $n=69$, with the fewest from Kahoolawe, $n=1$. A total of 10 haplotypes was observed of which five were from the $\mathrm{C}$ lineage, with haplotype $\mathrm{C} 1$ being the most common (Table II). The C1 haplotype was found from $52 \%$ (123 of 235, Table II) of the samples. Magnus et al. (2011) found the C1 haplotype to be the most common haplotype in the continental United States, while Delaney et al. (2009) found haplotype C1 to be the most common in Southern United States, and the second most common in Western United States. Four of the $\mathrm{C}$ lineage haplotypes $(\mathrm{C} 1, \mathrm{C} 2, \mathrm{C} 11$, and $\mathrm{C} 19)$ have been observed in samples from queen breeders in the continental United States (Delaney et al. 2009; Magnus et al. 2011). Delaney et al. (2009) using the Dra I test (a PCR-restriction fragment length polymorphism (RFLP) of the COI-COII intergenic region, Garnery et al. 1998) found that C1 and C2 accounted for 90 to $96 \%$ of the sampled Western and Southern United States queen breeder haplotypes. These proportions contrasted with the $50 \%$ reported by Magnus et al. (2011) using DNA sequence data. The remaining $\mathrm{C}$ lineage haplotype, C33, which was found in only two colonies from Maui, has been observed in feral honey bees from Oklahoma and Texas (Magnus et al. 2014).

Unlike genetic surveys on mainland bee populations using mtDNA sequence data, the Hawaiian populations had a high number of 
Table II. Frequency of Apis mellifera COI-COII haplotypes among seven Hawaiian Islands and three source types

\begin{tabular}{|c|c|c|c|c|c|c|c|c|c|c|c|c|}
\hline & \multirow[t]{2}{*}{$H_{d}$} & \multicolumn{10}{|c|}{ Haplotype } & \multirow[t]{2}{*}{ Total } \\
\hline & & $\mathrm{C} 1$ & $\mathrm{C} 2$ & $\mathrm{C} 11$ & $\mathrm{C} 19$ & $\mathrm{C} 33$ & M3 & M4c" & M7 & M70 & $\mathrm{O} 1$ & \\
\hline \multicolumn{13}{|l|}{ Island } \\
\hline Hawaii & 0.59 & 40 & - & 1 & - & - & 1 & 1 & 7 & 19 & - & 69 \\
\hline Kahoolawe & 0 & - & 1 & - & - & - & - & - & - & - & - & 1 \\
\hline Kauai & 0.52 & 25 & 2 & - & - & - & - & - & 12 & 1 & - & 40 \\
\hline Lanai & 0 & 21 & - & - & - & - & - & - & - & - & - & 21 \\
\hline Maui & 0.75 & 4 & - & 1 & - & 2 & - & - & 9 & 7 & - & 23 \\
\hline Molokai & 0.66 & 19 & - & - & 17 & - & - & - & 10 & - & - & 46 \\
\hline Oahu & 0.76 & 14 & 2 & - & 2 & - & - & - & 9 & 6 & 2 & 35 \\
\hline \multicolumn{13}{|l|}{ Source type } \\
\hline Feral & 0.70 & 20 & 1 & 1 & 9 & 1 & 1 & - & 9 & - & - & 42 \\
\hline Swarm & 069 & 15 & 1 & - & 5 & - & - & - & 15 & 2 & - & 38 \\
\hline Managed & 0.62 & 88 & 3 & 1 & 5 & 1 & - & 1 & 23 & 31 & 2 & 155 \\
\hline Total & 0.66 & 123 & 5 & 2 & 19 & 2 & 1 & 1 & 47 & 33 & 2 & 235 \\
\hline
\end{tabular}

$H_{d}$ haplotypic diversity

samples from the $M$ lineage (82 of $235,35 \%$; Table II) and a high diversity of $\mathrm{M}$ lineage haplotypes (4 of 10, $40 \%$; Table II) of observed haplotypes. This lineage was not found in a survey of queen breeders in continental United States (Magnus et al. 2011). The previously mentioned study by Delaney et al. (2009) using PCR-RFLP of mtDNA found that $2.8 \%$ of Western United States commercial queen breeders in 1994 had the M lineage (all were haplotype M3) and $1.1 \%$ of these breeders had it in 2004. Analysis of Southern United States queen breeders in the same study found that 4.8 and $2.7 \%$ of breeders had M lineage queens (M3, M4', M7, and M7' haplotypes) in 1993 and 2005, respectively. Previous studies of feral honey bee populations in mainland United States found that the M lineage accounted for $7 \%$ of sampled feral honey bees using mtDNA sequence data (Magnus et al. 2014). 18-26\% of feral honey bees in a wildlife refuge in Texas using PCR-RFLP analysis of mtDNA COI gene (Pinto et al. 2004) and $37 \%$ of feral honey bees in the Southern United States using mtDNA RFLP analysis (Schiff et al. 1994).

A total of four haplotypes from the $\mathrm{M}$ lineage were observed, with haplotype M70 and M7 being the most common (Table II). Of the $\mathrm{M}$ lineage haplotypes, only M3 and M7 have been found in continental United States (Delaney et al. 2009; Magnus et al. 2014). while haplotype M4c" has been observed in France (Rortais et al. 2011). The haplotype M70 has not been reported before (based on data from GenBank) and may be unique to Hawaii. This haplotype is similar to haplotype M8' (Garnery et al. 1998; Rortais et al. 2011) from Spain and France. The DNA sequence of M70 differs from M8' at two nucleotide sites (positions 53, T to A; and 206, A to $\mathrm{G}$ in our alignment). Finally, one haplotype of the O lineage, haplotype O1, was observed; this haplotype has been found in the continental United States but only in feral honey bee populations in Missouri, Mississippi, and Oklahoma (Magnus et al. 2014).

We found significant genetic differentiation based on pairwise $F_{\text {ST }}$ significance tests on haplotype frequencies among the island populations and source types (Tables III and IV, Kahoolawe was excluded due to a sample size of one). This suggests that honey bees are not often exchanged among islands and that most islands harbor a unique collection of haplotypes. The estimates of genetic distance (as $F_{\text {ST }}$ values) were the highest among Hawaii, Kauai, Maui, Molokai, and Oahu, 
Table III. Pairwise estimates of divergence $\left(F_{\mathrm{ST}}\right)$ among $A$. mellifera Hawaiian Island populations (below diagonal) and $N_{m}$ (above diagonal)

\begin{tabular}{lllllll}
\hline Island & Hawaii & Kauai & Lanai & Maui & Molokai & Oahu \\
\hline Hawaii & - & 6.6 & 1.9 & 2.8 & 2.6 & 12.7 \\
Kauai & $0.070^{*}$ & - & 1.7 & 2.3 & 3.7 & 13.8 \\
Lanai & $0.0206^{*}$ & $0.229^{*}$ & - & 0.4 & 0.9 & 1.1 \\
Maui & $0.151^{*}$ & $0.176^{*}$ & $0.535^{*}$ & - & 2.4 & 14.7 \\
Molokai & $0.159^{*}$ & $0.120^{*}$ & $0.352^{*}$ & $0.170^{*}$ & - & 7.0 \\
Oahu & $0.038^{*}$ & 0.035 & $0.310^{*}$ & 0.033 & 0.067 & - \\
\hline
\end{tabular}

Kahoolawe was excluded due to the sample size of one

$* P<0.05$, based on 16,000 permutations

paired with Lanai, with $F_{\text {ST }}$ values ranging from 0.206 to 0.535 (Table III). This is due to the population on Lanai consisting of a single haplotype, $\mathrm{C} 1$, among the 21 colonies sampled. The most similar island populations were Oahu and Maui (0.033) and Oahu and Kauai (0.035). The gene flow parameter, $N_{m}$ (Slatkin 1981). which is an estimate of the number of migrants shared between populations, ranged from as low as 0.4 (Lanai to Maui) to as high as 14.7 (Maui to Oahu) (Tables III and IV). Using the same tests of differentiation, bees sourced from managed populations were significantly different from those in the swarm and feral samples $\left(F_{\mathrm{ST}=} 0.075\right.$ and 0.051 , $P=0.001$ and 0.005 , respectively) (Table III). Like studies on the mainland United States (Magnus et al. 2014). managed and unmanaged populations of honey bees seem distinct from one another in Hawaii as well.

Significant population structure among islands has also been observed in a study of $A$. mellifera

Table IV. Pairwise estimates of divergence $\left(F_{\mathrm{ST}}\right)$ between swarm, feral, and managed samples (below diagonal) and $N_{m}$ (above diagonal)

\begin{tabular}{llll}
\hline Source & Swarm & Feral & Managed \\
\hline Swarm & - & 45.0 & 6.2 \\
Feral & 0.011 & - & 9.3 \\
Managed & $0.075^{*}$ & $0.051^{*}$ & - \\
\hline
\end{tabular}

$* P<0.05$, based on 16,000 permutations populations from the Canary Islands by De La Rua et al. (2001). Among five Canary Islands which were studied, they observed $F_{\text {ST }}$ values up to 0.502 using DNA sequence variation of the same COI-COII region used here. In contrast to this study, they observed low levels of genetic diversity within island populations. Another study on COI-COII genetic variation of $A$. m. mellifera populations from Europe found significant levels of $F_{\text {ST }}$ genetic differentiation between populations in Ireland and England relative to continental populations in Scandinavia (Jensen et al. 2005).

Among the seven Hawaiian Islands that samples were available from, haplotype $\mathrm{C} 1$ was the only haplotype common to all islands with adequate $(n>1)$ sample sizes (Table II). This haplotype is very common among queen breeders in the continental United States as well (Magnus et al. 2011). Of the other $C$ lineage haplotypes, $C 2$ was only found on Kauai and Oahu and in the single sample from Kahoolawe, C11 on Hawaii and Maui, C19 on Molokai and Oahu, and C33 only on Maui (Table II). Of the M lineage haplotypes, M7 and M70 were both found on Hawaii, Kauai, Maui, and Oahu; M7 was additionally found on Molokai. The O lineage haplotype, O1, was only found on Oahu, where it accounted for $6 \%$ of the samples.

Haplotypic diversity was highest for Maui and Oahu ( $H_{d}=0.75$ and 0.76 , respectively), with five and six haplotypes each, followed by Molokai ( $H_{d}=0.66$, three haplotypes), Hawaii $\left(H_{d}=0.59\right.$, six haplotypes), and Kauai $\left(H_{d}=0.52\right.$, four 
haplotypes) (Table II). In 1857, Oahu was the first island to have honey bees introduced, and Oahu subsequently served as the source of bees introduced to Kauai and Hawaii in the late 1890s (Roddy and Arita-Tsutsumi 1997). Perhaps the extended history of introductions and beekeeping in Oahu explains why haplotypic diversity is higher, in spite of Oahu being smaller and housing fewer colonies than the Big Island (Figure 1). The high proportion of $\mathrm{M}$ lineage honey bees on the seven islands sampled here, and the large number of haplotypes observed of this lineage relative to mainland honey bee populations suggests that this matriline has persisted well on the Hawaiian Islands compared to mainland populations. There is also genetic evidence for introduced honey bees of the $\mathrm{M}$ lineage persisting in other Pacific Islands. A study of honey bees in Tasmania by Oldroyd et al. (1995) found evidence that A. m. mellifera was well established on Tasmania and had hybridized with populations of $A$. $m$. ligustica based on mtDNA RFLP and allozyme data. They found that the distribution of the two lineages in Tasmania was correlated with temperature and elevation, with A. m. mellifera being found in cooler mountain regions. In the Kangaroo Islands, Australia, Koulianos and Crozier (1996) found that honey bees from there resembled $A$. $m$. ligustica morphologically but had the characteristics of $A . m$. mellifera based on DNA sequence data of four regions of the mitochondrial genome. They concluded that the Kangaroo Island population was established by hybrids of the two subspecies.

The commonness of the $\mathrm{M}$ derived haplotypes among feral (24\%) and swarm (45\%) sources in Hawaii may suggest that bees of the $\mathrm{M}$ lineage are particularly well adapted to environmental conditions on the islands, yet it is also possible that genetic drift or the unique importation and sequestration history of Hawaii has led to their unusual commonness there. Because honey bee semen has been imported to Hawaii since the importation ban on colonies, an analysis of nuclear genetic diversity of Hawaiian bees should make an interesting complement to the mtDNA study here.

In the native range of the $\mathrm{M}$ lineage of A. mellifera in Europe, there is a concern for the conservation of this lineage (Soland-Reckeweg et al. 2009; Rortais et al. 2011). Population genetics studies using mtDNA COI-COII, microsatellite analysis, or SNP analysis have revealed that hybridization of $A . m$. mellifera honey bees is occurring with $\mathrm{C}$ lineage honey bees in Europe (Jensen et al. 2005; Soland-Reckeweg et al. 2009; Pinto et al. 2014). The use of the mtDNA COICOII genetic marker has been found to be useful in distinguishing potential $\mathrm{M}$ lineage breeder colonies for maintaining this lineage in Europe. For example, Strange et al. (2008) found that PCRRFLP analysis of the Landes A. m. mellifera ecotype (M lineage) in France was useful in discriminating this ecotype from introduced $\mathrm{C}$ lineage colonies.

It has been estimated that on the mainland United States, as few as 500 breeder queens have been used to produce approximately 900,000 daughter queens for commercial sale in continental United States (Schiff and Sheppard 1995, 1996; Delaney et al. 2009). which perhaps explains the lack of mitochondrial haplotype diversity (Magnus et al. 2011, 2014). The difference in haplotypes found in Hawaii relative to mainland United States could be due to queen breeders in Hawaii not using queens collected from feral colonies and swarms, but instead using queens from breeder stocks imported from continental United States, at least through the 1980s (Tillman 1982).

The mtDNA data from this study provides evidence that Hawaiian honey bee populations are different from those found in the continental United States. High levels of mtDNA COI-COII haplotype variation were observed among most of the Hawaiian Islands, yet there seems to be little exchange of honey bees among islands. Despite the predominance of $\mathrm{C}$ lineage honey bees in continental United States, the discovery of a high proportion of $\mathrm{M}$ derived haplotypes in Hawaii suggests that bees from this matriline may have persisted in both wild and managed populations for more than 100 years, assuming the importation ban has been effective. Given the importance of commercial queen breeding in Hawaii, M lineage Hawaiian honey bees may become important for increasing genetic diversity of honey bees in continental United States and Canada. Future research should focus on genetic diversity of queen 
breeders in Hawaii to see if M lineage haplotypes are present among Hawaiian queen breeders, using both mitochondrial and microsatellite DNA markers.

\section{ACKNOWLEDGMENTS}

We thank the numerous beekeepers in the state of Hawaii along with Lauren Rusert, Stacey Chun, and Craig Kaneshige for assisting with sample collection. This research was supported in part by the University of Arkansas, Arkansas Agricultural Experiment Station, and the Hawaii Department of Agriculture Apiary Program.

\section{Diversité génétique de l'ADN mitochondrial des abeilles (Apis mellifera) à Hawaï}

\section{Apidae / biogéographie / île / lignée / haplotype / ADNmt}

Genetische Diversität der mitochondrialen DNA von Honigbienen, Apis mellifera, in Hawaii

\section{Apidae / mtDNA / genetische Diversität / Inselbiogeographie}

\section{REFERENCES}

Anonymous (2005) USDA Foreign Agricultural Service. Canada Honey Production and Trade Update 2005. GAIN Report Number: CA5083

Anonymous (2014) Honey. USDA Agricultural Statistics Board, National Agricultural Statistics Service. Washington, DC

Chapman, N.C., Lim, J., Oldroyd, B.P. (2008) Population genetics of commercial and feral honey bees in western Australia. J. Econ. Entomol. 101, 272-277

Danka, R.G., Harris, J.W., Villa, J.D. (2010) Hygienic responses to Varroa destructor by commercial and feral honey bees from the Big Island of Hawaii before exposure to mites. Bee Culture 138, S11-S14

De La Rua, P., Galian, J., Serrano, J., Moritz, R.F.A. (2001) Genetic structure and distinctness of Apis mellifera L. populations from the Canary Islands. Molec. Ecol. 10, 1733-1742

Delaney, D.A., Meixner, M.D., Schiff, N.M., Sheppard, W.S. (2009) Genetic characterization of commercial honey bee (Hymenoptera, Apidae) populations in the United States by using mitochondrial and microsatellite markers. Ann. Entomol. Soc. Amer. 102 , 666-673
Eckert, J.E. (1950) The development of resistance to American foulbrood by honey bees in Hawaii. J. Econ. Entomol. 43, 562-564

Eckert, J.E. (1951) Rehabilitation of the beekeeping industry in Hawaii, p. 29. Industrial Research Advisory Council, Honolulu

Excoffier, L., Lischer, H.E.L. (2010) Arlequin suite ver 3.5: a new series of programs to perform population genetics analyses under Linux and Windows. Molec. Ecol. Res. 10, 564-567

Franck, P., Garnery, L., Loiseau, A., Oldroyd, B.P., Hepburn, H.R., Solignac, M., Cornuet, J.M. (2001) Genetic diversity of the honeybee in Africa: microsatellite and mitochondrial data. Heredity 86, 420-430

Fullaway, D.T. (1909) Hawaiian bees and honey. Paradise of the Pacific 22, 27-28

Garnery, L., Franck, P., Baudry, E., Vautrin, D., Cornuet, J.M., Solignac, M. (1998) Genetic diversity of the west European honey bee (Apis mellifera mellifera and A. m. iberica) I. Mitochondrial DNA. Genet. Select. Evol 30 (Suppl 1), S31-S47

Jensen, A.B., Palmer, K.A., Boomsma, J.J., Pedersen, B.V. (2005) Vary degrees of Apis mellifera ligustica introgression in protected populations of the black honeybee, Apis mellifera mellifera, in northwest Europe. Molec. Ecol. 14, 93-106

Keck, C.B. (1937) Presidential address: observations on beekeeping in Hawaii. Proc. Hawaiian Entomol. Soc. 9, 461-467

Koulianos, S., Crozier, R.H. (1996) Mitochondrial DNA sequence data provies further evidence that honeybees of Kangaroo Island, Australia are of hybrid origin. Apidologie 27, 165-174

Lansman, R.A., Shade, R.O., Shapira, J.F., Avise, J.C. (1981) The use of restriction endonucleases to measure mitochondrial DNA sequence relatedness in natural populations. III. Techniques and potential applications. J. Molec. Evol. 17, 214-226

Magnus, R.M., Szalanski, A.L. (2010) Genetic evidence for honey bees (Apis mellifera L.) of Middle Eastern lineage in the United States. Sociobiol. 55, 285-296

Magnus, R.M., Tripodi, A.D., Szalanski, A.L. (2011) Mitochondrial DNA diversity of honey bees, Apis mellifera L. (Hymenoptera: Apidae) from queen breeders in the United States. J. Apic. Sci. 55, 5-17

Magnus, R.M., Tripodi, A.D., Szalanski, A.L. (2014) Mitochondrial DNA diversity of honey bees (Apis mellifera) from unmanaged colonies and swarms in the United States. Biochem. Genet. 52, 245-257

Meixner, M.D., Pinto, M.A., Bouga, M., Kryger, P., Ivanova, E., Fuchs, S. (2013) Standard methods for characterizing subspecies and ecotypes of Apis mellifera . J. Apic. Res. 52, 1-27

Messing, R.H. (1991) Status of beekeeping in the Hawaiian Islands. Bee World 72, 147-160

Nieman, R.E. (1942) Liquid gold. Paradise of the Pacific 54, 17-21 
Oldroyd, B.P., Cornuet, J.-M., Rowe, D., Rinderer, T.E., Crozier, R.H. (1995) Racial admixture of Apis mellifera in Tasmania, Australia: similarities and differences with natural hybrid zones in Europe. Heredity 74, 315-325

Pinto, M.A., Rubink, W.L., Coulson, R.N., Patton, J.C., Johnston, J.S. (2004) Temporal pattern of Africanization in a feral honeybee population from Texas inferred from mitochondrial DNA. Evolution 58, 1047-1055

Pinto, M.A., Henriques, D., Chávez-Galarza, J., Kryger, P., Garnery, L., Zee, R.V.D., Dahle, B., Solad-Reckeweg, G., De la Rua, P., Dall'Olio, R., Carreck, N.L., Johnston, J.S. (2014) Genetic integrity of the dark European honey bee (Apis mellifera mellifera) from protected populations: a genome-wide assessment using SNPs and mtDNA sequence data. J. Apic. Res. 53, 269-278

Roddy, K.M., Arita-Tsutsumi, L. (1997) A history of honey bees in the Hawaiian Islands. J. Hawaii. Pac. Agric. 8, 59-70

Roderick, G.K., Gillespie, R.G. (1998) Speciation and phylogeography of Hawaiian terrestrial arthropods. Molec. Ecol. 7, 519-531

Rortais, A., Arnold, G., Alburaki, M., Legout, H., Garnery, L. (2011) Review of the DraI COI-COII test for the conservation of the black honeybee (Apis mellifera mellifera ). Conserv. Genet. Resour. 3, 383-391

Ruttner, F. (1988) Biogeography and taxonomy of honeybees. Springer, Berlin, Germany

Sambrook, J., Russell, D.W., Cold Spring Harbor Laboratory Press (2001) Molecular cloning. Cold Spring Harbor, NY

Schiff, N.M., Sheppard, W.S. (1995) Genetic analysis of commercial honey bees (Hymenoptera: Apidae) from Southeastern US. J. Econ. Entomol. 88, 1216-1220

Schiff, N.M., Sheppard, W.S. (1996) Genetic differentiation in the queen breeding population of the Western United States. Apidologie 27, 77-86

Schiff, N.M., Sheppard, W.S., Loper, G.M., Shimanuki, H. (1994) Genetic diversity of feral honey bee (Hymenoptera: Apidae) populations in the Southern United States. Ann. Entomol. Soc. Am. 87, 842-848

Sheppard, W.S. (1988) Comparative study of enzyme polymorphism in United States and European honey bee
(Hymenoptera, Apidae) populations. Ann. Entomol. Soc. Am. 81, 886-889

Sheppard, W.S. (1989a) A history of the introduction of honey bee races into the United States; part I of a twopart series. Am. Bee J. 129, 617-619

Sheppard, W.S. (1989b) A history of the introduction of honey bee races into the United States; part II of a twopart series. Am. Bee J. 129, 664-667

Sheppard, W.S., Meixner, M.D. (2003) Apis mellifera pomonella, a new honey bee from the Tien Shan Mountains of Central Asia. Apidologie 34, 367-375

Sheppard, W.S., Smith, D.R. (2000) Identification of African-derived bees in the Americas: a survey of methods. Ann. Entomol. Soc. Am. 93, 159-176

Sheppard, W.S., Arias, M.C., Grech, A., Meixner, M.D. (1997) Apis mellifera ruttneri, a new honey bee subspecies from Malta. Apidologie 28, 287-293

Slatkin, M. (1981) Estimating levels of gene flow in natural populations. Genetics 99, 323-335

Soland-Reckeweg, G., Heckel, G., Neumann, P., Fluri, P., Excoffier, L. (2009) Gene flow in admixed populations and implications for the conservation of the Western honeybee, Apis mellifera. J. Insect Conserv. 13, 317328

Strange, J.P., Garnery, L., Sheppard, W.S. (2008) Morphological and molecular characterization of the Landes honey bee (Apis mellifera L.) ecotype for genetic conservation. J Insect Conserv 12, 527-537

Szalanski, A.L., Magnus, R.M. (2010) Mitochondrial DNA characterization of Africanized honey bee (Apis mellifera L.) populations from the USA. J. Apic. Res. 49, 177-185

Taylor, D.B., Peterson II, R.D., Szalanski, A.L., Petersen, J.J. (1997) Mitochondrial DNA variation among Muscifurax spp. (Hymenoptera: Pteromalidae), pupal parasitoids of filth flies (Diptera). Ann. Entomol. Soc. Am. 90, 814-824

Tillman, T. (1982) Queen rearing in Hawaii. Am. Bee J. $122,618-621$

Wright, S. (1965) The interpretation of population structure by F-statistics with special regard to systems of mating. Evolution 19, 395-420 